\title{
Social Psychology Quarterly
}

\section{Perceptions of Economic and Behavioral Differences Between Blacks and Whites: Racial Attitudes of White Americans and Status Generalization \\ Stan A. Kaplowitz, Clifford L. Broman and Bradley J. Fisher \\ Social Psychology Quarterly 2006 69: 367 \\ DOI: $10.1177 / 019027250606900405$}

The online version of this article can be found at:

http://spq.sagepub.com/content/69/4/367

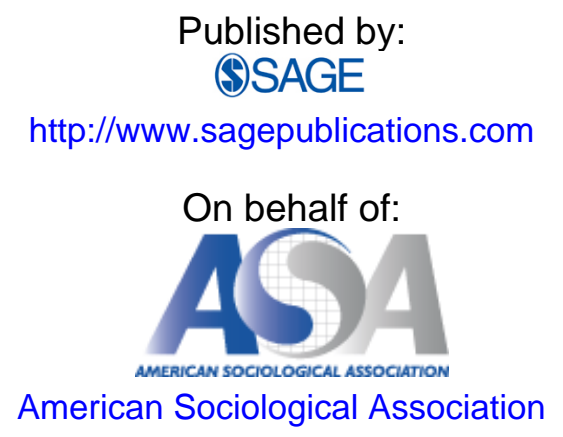

Additional services and information for Social Psychology Quarterly can be found at:

Email Alerts: http://spq.sagepub.com/cgi/alerts

Subscriptions: http://spq.sagepub.com/subscriptions

Reprints: http://www.sagepub.com/journalsReprints.nav

Permissions: http://www.sagepub.com/journalsPermissions.nav 


\title{
Perceptions of Economic and Behavioral Differences Between Blacks and Whites: Racial Attitudes of White Americans and Status Generalization*
}

\author{
STAN A. KAPLOWITZ \\ CLIFFORD L. BROMAN \\ Michigan State University \\ BRADLEY J. FISHER \\ Missouri State University
}

\begin{abstract}
A telephone survey of Michigan residents provided statistics about the economic conditions and undesirable behavior of white Americans and asked respondents to estimate the corresponding statistics for blacks. Data from white respondents showed that the greater the perceived racial difference $(P R D)$ in rates of undesirable behavior, the more blacks were seen as not trying to better themselves and the less blacks were viewed as experiencing discrimination. The greater the PRD in economic status, especially controlling for education, the more respondents saw racial discrimination as continuing. Controlling for the PRD in Undesirable Behavior, however, the PRD in economic status had little effect on the belief that blacks do not make effort. Implications of these results for status generalization processes are discussed. Because respondents underestimated all racial differences, accurate knowledge of racial statistics might increase both the belief that discrimination continues and the belief that blacks fail to make an effort.
\end{abstract}

Many statistics show that black Americans are economically less well off than whites and also display higher rates of some deviant behaviors. Social scientists often quote these figures and typically regard them as very important in our understanding of racial inequality. Kaplowitz, Fisher and Broman (2003) showed that much of the general public has only a crude sense of what these data show. On the one hand, the large majority of respondents were aware that blacks are economically worse off than

* An earlier version of this paper was presented at the annual meetings of the American Sociological Association held in Chicago in August 1999. We thank Timothy Brezina, Edward L. Fink, Steven J. Gold, William B. Hixson Jr., Vivian S. Hixson, the editor of $S P Q$ and anonymous reviewers for their valuable comments. The data are taken from the July/August 1995 State of the State Survey, conducted by the Survey Research Division of the Institute for Public Policy and Social Research at Michigan State University. The analyses, interpretations, and conclusions are solely those of the authors. Direct communications to Stan Kaplowitz, Department of Sociology, Michigan State University, East Lansing, MI 488241111; (517)353-6745; fax (517)432-2856; kaplowi1@ msu.edu. whites and also show higher rates of certain socially disapproved behaviors (such as births outside of marriage). On the other hand, respondents vary considerably in their beliefs about the size of these differences between races.

The primary focus of this paper is to explore the extent and direction of relationship between these estimates of racial statistics (which we call statistical perceptions) and two racial attitudes: the belief that blacks do not help themselves and the belief that blacks suffer discrimination. Then we use our findings and the comparison between the statistical perceptions and the actual data to address the following questions: Would accurate information about these statistics make white people more sympathetic to blacks, or less so? How well does status generalization theory account for whites' attitudes towards blacks?

\section{Prior Literature}

In the 1960s, evidence that blacks were substantially worse off than whites was often used as a means of justifying government 
assistance to black people. President Kennedy (1964) quoted statistics on blacks' economic disadvantage as part of his case for civil rights legislation. In chapter 7 of the 1968 Report of the National Advisory Commission on Civil Disorders (the Kerner Commission) the extent of black's economic disadvantage was documented as part of the case for national action to improve their situation.

Some social science literature however, suggests that the more whites perceive blacks to be poor, the more they will accept negative stereotypes of blacks. Myrdal (1944: 75-78) suggests that black people's low socioeconomic position is not only a consequence of white prejudice and discrimination, but also in turn, "gives support to white prejudice." Sniderman and Piazza (1993) go further and suggest that the belief that blacks occupy low socioeconomic position may contribute to the stereotype that blacks are lazy and irresponsible, even among whites who did not harbor prior prejudice against blacks.

Several empirical studies are consistent with this prediction. Bobo and Massagli (2001) found that the lower the perceived economic status of a minority group, the greater the white respondents' tendency to rate the group's dispositional traits unfavorably. Even more direct evidence is provided by Brezina and Winder (2003), who found that the greater the economic disadvantage white respondents perceived blacks to suffer, the more these respondents viewed blacks as lazy.

Brezina and Winder explain this finding via Ridgeway's (2000) status generalization theory, which holds that people infer the task ability of others from the levels of rewards or resources that those other receive (for evidence see e.g., Cook 1975). Brezina and Winder view these status generalization processes as occurring even among those who accept a structural explanation for the differences between groups.

We propose, however, that nowadays, negative stereotyping of blacks is not a consequence of the perception that blacks are poorer. Rather, it is related primarily to the perception that blacks display higher rates of socially undesirable behaviors than whites.

Katz and Hass (1988) state that the degree to which blacks are viewed as deviant (i.e., not following the Protestant work ethic to improve their lot) is one of two important dimensions of whites' racial attitudes. A second dimension is the degree to which whites view blacks as disadvantaged (i.e., receiving lesser opportunity). Both of these dimensions are strong predictors of whites' attitudes towards policies designed to assist blacks (see, e.g., Kluegel 1990). Thus, we examine the effect of beliefs about racial differences in economic status and undesirable behavior both on negative stereotypes, and on beliefs about whether racial discrimination is a continuing problem for blacks.

\section{The Causal Relationship between Attitudes and Statistical Perceptions.}

Hammond (1948) strongly suggests that statistical perceptions reflect attitudes. Both Brezina and Winder (2003) and the present authors, however, assume that statistical perceptions influence attitudes. Social psychologists typically assume that people start with empirical observations and develop attributions to explain them (see, e.g., Heider 1958). According to this view, whether one has been exposed directly to a set of statistics or has inferred them from experience (either direct or vicarious), statistical perceptions are summaries of one's impressions of the empirical world. By contrast, the racial attitudes that we measure assume not only impressions of the empirical world but also causal attributions for those impressions.

The plausibility of this causal direction is shown by the fact that persuasion campaigns often include presentation of statistics (hence the saying "lies, damned lies, and statistics"). Moreover, in the literature on racial attitudes that we cited above, it is assumed that people's beliefs about these statistics affect their attitudes.

\section{Hypotheses}

These hypotheses involve the Perceived Racial Difference (PRD) in a statistic, which we conceptualize as the difference between the respondent's belief about a statistic about blacks and the corresponding actual statistic about whites. Our first hypothesis follows from the findings of Brezina and Winder (2003). 
Hypothesis 1: There is a positive bivariate correlation between the perceived racial difference (PRD) in economic status and the degree to which whites see blacks as failing to make an effort to improve their situation.

In explaining the hypotheses that follow, we first note that both the economic status someone achieves and the extent of his or her undesirable behavior can be explained in two alternative ways. One category of explanation or attribution is internal and focuses on the individual actor's traits. The other type focuses on external factors, including situational or structural disadvantages.

Americans generally prefer to make internal attributions for behavior, even in the face of evidence for situational causes (see Al-Zahrani and Kaplowitz 1993; Miller 1984; Ross 1977). This is especially true where the behavior is viewed as unusual and socially undesirable (see Jones and Davis 1965). Thus the more that someone believes that undesirable behaviors (that violate the Protestant work ethic) are a distinctive characteristic of blacks, the more that person will regard these behaviors as evidence that blacks have negative traits (such as unwillingness to make an effort), which cause these behaviors.

Hypothesis 2: The greater the PRD in rates of undesirable behaviors, the more respondents will believe that blacks do not make the effort to improve their situation.

While evidence suggests that most Americans prefer internal explanations for behavior, economic inequality can be given either an individualist or a structuralist explanation (see Kluegel and Smith 1986). In fact, Brezina and Winder (2003:409) demonstrate that Americans see both structure and individual traits as contributing substantially to economic success. Regarding the black-white economic gap, Kluegel (1990) shows that although many Americans explain this gap individualistically, others explain it in terms of structure (including racial discrimination) and that many invoke both explanations.

Hypothesis 3: There is a strong positive bivariate correlation between the PRD in economic status and the PRD in undesirable behavior.
Both explanations of the black-white economic gap are consistent with Hypothesis 3. For those with an individualistic view, laziness or lack of effort causes undesirable behavior, which leads in turn to poverty. For those with a structural view, lack of opportunity for blacks encourages poverty, which in turn causes undesirable behavior (for such an argument, see Report of the National Advisory Commission 1968: ch. 7).

Hypothesis 4a: Controlling for the PRD in undesirable behavior, the PRD in economic status has a minimal effect on the belief that blacks do not make the effort to improve their situation. However:

Hypothesis 4b: Controlling for the PRD in economic status, the PRD in undesirable behavior has a substantial effect on the belief that blacks do not make the effort to improve their situation.

We offer two rationales for Hypothesis 4a. First, if Hypothesis 2 and Hypothesis 3 are correct, it is quite plausible that the bivariate relationship between negative stereotyping and the PRD in economic status is spurious. Second, the belief that blacks are substantially poorer than whites does not require invocation of negative stereotypes to explain this gap. Instead, one can explain the gap as a consequence of lack of opportunity for blacks (including discrimination). Hypothesis $4 \mathrm{~b}$ follows from our prior assertion that undesirable behavior leads to dispositional attributions.

While economic differences between races are ambiguous as to attribution, a difference in the economic status of blacks and whites with the same level of education is much less so. Such a difference negates a common individualistic explanation (i.e., racial differences in making the effort to get an education). In fact, not only is education positively associated with income, but Americans frequently are told of this relationship and believe in it strongly. ${ }^{1}$ Thus, we propose:

\footnotetext{
${ }^{1}$ In fact, the first author often asks students to estimate the correlation between income and education and finds that most offer an estimate considerably higher than the actual figure.
} 
Hypothesis 5: The greater the PRD in economic status, controlling for education, the greater the belief in the existence of continuing discrimination against blacks.

Armstrong (1991) found support for Hypothesis 5 using a college student sample.

\section{Racial Attitudes and Misperceiving Reality}

Kinder and Sears (1981: 416) state that whites' negative attitudes towards blacks are based on "early learned stereotypes" rather than "contemporary racial experiences," suggesting that they are based on misperception of reality. In this vein, Brezina and Winder (2003:406-407) draw on their results and on Gilens (1996) to suggest that negative stereotyping of blacks by whites is a result of exaggerating the correlation between race and economic status.

To evaluate these claims accurately, one needs two kinds of information: (1) the magnitude and direction of the relationship between relevant perceived racial differences and racial attitudes, and (2) valid comparisons between the actual and the perceived racial differences on some statistics. The present study is the only one that provides both kinds of information. Thus it offers the most valid available assessment of the change in attitudes to be expected if the public's knowledge were more accurate.

\section{Implications for Status Generalization Theory}

The experimental literature cited above shows that status generalization processes operate when evaluators know the rewards that people have received but lack any other evidence of the merit of those under evaluation. But do these processes adequately explain evaluations in situations (such as racial attitudes) where evaluators may have independent impressions of the merit of those who are being evaluated? Brezina and Winder (2003) make the case that these processes do explain such racial attitudes; in this paper we consider the implications of our findings for this question.

\section{DATA AND METHODS}

The data were gathered in 1995 in a random-digit-dialing phone survey of the Michigan population, conducted by the Survey Research Division at the Institute for Public Policy and Social Research at Michigan State University. Our analysis is restricted to the 823 white respondents. The refusal rate, (the proportion of all potentially eligible cases in which a respondent refused to take part in an interview), was 21.8 percent. The contact rate, (the proportion of all cases in which some responsible member of the housing unit was reached by the survey), was 96.4 percent. The individual cases were weighted differentially to make the sample more representative of the state'a population. Kaplowitz et al. (2003), however, found that such weighting resulted in only very minor changes in the results. Consequently the analysis reported here omits these weights.

\section{Statistical Perception Questions}

These questions were introduced by saying "Now, we'd like to find out how you think the actual situation of the typical black person or family compares with the situation of the typical white person or family. To help you out, we will give you a recent figure for whites. Please keep that figure in mind. We will then ask you what you think the situation is for blacks."

The questions, in this order, were: (1) "The average income of white families is about $\$ 32,000$. What do you think is the average income of black families?" (2) "The average income of white male college graduates is about $\$ 31,000$. What do you think is the average income of black male college graduates?" (3) "Out of every 100 whites, approximately 11 are receiving welfare. Out of every 100 blacks, how many do you think are receiving welfare?" (4) "Out of every 100 white babies born in the United States in the last few years, approximately 22 were born to unwed mothers. Out of every 100 black babies, how many do you think were born to unwed mothers"? (5) "Out of every 100 whites, nine have incomes below the poverty 
line. Out of every 100 blacks, how many do you think are living in poverty?"

Questions 1,2, and 5 deal with perceived economic status; question (2) also controls for education. Questions 3 and 4 deal with behavior that is viewed as undesirable, for violating norms of self-discipline regarding work or sexual behavior. Although many would say that receiving welfare is related strongly to one's economic status, Gilens (1999) shows that most Americans view most welfare recipients as undeserving "welfare cheats."

We conceptualize the perceived racial difference (PRD) of a statistical perception as the difference between the respondent's estimate of a statistic for blacks and his or her estimate of the corresponding statistic for whites. To operationalize this variable in the current research, we assume that the respondent's estimate of the white statistic is the statistic about whites that was provided in the survey. The direction of subtraction is such that the difference between the actual statistics for the two races is always positive.

Racial Attitude Questions. The belief that blacks fail to make the effort to get ahead was measured by the response to (1) "Blacks do not stress education" and (2) "Most blacks on welfare could get a job if they really tried." These items tap two of the core beliefs in Katz and Hass's (1988) Anti-Black Scale, which measures the degree to which blacks are perceived as "lacking the inner resources to improve their lot." In addition, the belief that blacks are lazy is one of the most pervasive stereotypes of blacks and holds a substantial relationship to negative attitudes towards welfare (see Gilens 1999:Ch 7).

Beliefs about the extent of current discrimination against blacks were measured by responses to two questions: (3) "Discrimination still limits opportunities for blacks" and (4) "On the average, blacks or African Americans have worse jobs, housing and income than white people. How important a factor would you say that racial discrimination is in accounting for this?" All except the last question above were measured on Likert scales in which (1) denoted "strongly disagree" and (5) signified "strongly agree." The last question was measured on a scale ranging from 1 ("not important at all") to 3 ("very important").

\section{Structural Equation Modeling}

Because several variables of interest are latent variables with more than one observed indicator, we analyze the data with structural equation modeling (SEM; see, e.g., Bollen 1989) using AMOS 5. Moreover, two of the attitude questions, 2 and 4 above, were asked of only half or fewer of the respondents (chosen randomly). According to Arbuckle (1996) and Arbuckle and Wothke (1999:332), the full information maximum likelihood method used by AMOS is superior for estimating coefficients where there is missing data. This method avoids the massive loss of cases that can result from listwise deletion, while avoiding the biases associated with other methods (Allison 2002).

SEM assumes that all variables are normally distributed. We evaluated this assumption by examining the skew and kurtosis of all observed variables. One of these variables (the PRD in college graduate income) showed gross departures from normality. Therefore we transformed this variable before conducting the SEM analysis. ${ }^{2}$

\section{Univariate Descriptives}

For descriptives of the statistical perception variables, see Table 1 . For all statistical perceptions, the mean PRD is smaller than the actual racial difference (ARD). For two of the statistical perceptions, (births outside marriage and male college graduate income), the mean PRD is less than half of the ARD.

In short, the typical respondent underestimated, sometimes massively, black-white differences on both economic status and undesirable behavior. For all statistics except welfare, this difference between the PRD and the ARD is significant at $p<.001$. For welfare, the difference is significant at $p<.05$.

\footnotetext{
${ }^{2}$ In the transformation we took the square root of the absolute value of the PRD, but preserved the original sign. Thus a PRD of +4 (note that a unit of this variable is $\$ 1,000$ ) would be transformed to +2 and a PRD of -4 would be transformed to -2 .
} 
Table 1 Means of Perceived Racial Differences and Actual Racial Differences on Statistical Perceptions

\begin{tabular}{lccccc}
\hline \hline & $\begin{array}{c}\text { \% Births } \\
\text { Outside } \\
\text { Marriage }\end{array}$ & $\begin{array}{c}\text { \% on } \\
\text { Welfare }\end{array}$ & $\begin{array}{c}\text { \% in } \\
\text { Poverty }\end{array}$ & $\begin{array}{c}\text { Family } \\
\text { Income } \\
(\$ 1,000)\end{array}$ & $\begin{array}{c}\text { Income Male } \\
\text { College Grads } \\
(\$ 1,000)\end{array}$ \\
\hline $\begin{array}{l}\text { Statistic About Whites } \\
\quad \text { Provided to Respondent (a) }\end{array}$ & 22 & 11 & 9 & 32 & 31 \\
$\begin{array}{l}\text { Mean Estimate of Statistic } \\
\text { about Blacks (b) }\end{array}$ & 38.1 & 27.9 & 26.9 & 22.45 & 28.63 \\
$\begin{array}{l}\text { Mean PRD = |b-a| } \\
\text { (SD of PRD) }\end{array}$ & 16.1 & 16.9 & 17.9 & 9.41 & 2.37 \\
Actual Racial Difference & $(16.2)$ & $(17.2)$ & $(16.2)$ & $(6.27)$ & $(4.82)$ \\
\hline
\end{tabular}

Notes: $N$ per variable ranges between 770 and 779 . The actual racial difference is the difference between the actual black and the actual white statistics. For all statistics except welfare, the statistic provided (first row) equals the actual white statistic. For data about black respondents and for the sources of all of the actual statistics except welfare, see Kaplowitz et al. (2003). For welfare dependence, the actual white and black statistics are 5.7 percent and 24.1 percent respectively. For percentage receiving some means-tested form of public assistance (i.e., AFDC or other non-SSI cash assistance) see United States Bureau of the Census (1990: 124, Table 14). Standard deviations in parentheses.

For descriptive statistics on the racial attitude measures, see Table 2.

\section{Confirmatory Factor Analysis}

Our initial measurement model, in which we assumed that perceived racial differences in poverty and family income formed one economic inequality factor, was not satisfactory. We then tested a revised measurement model, in which these two PRDs were viewed as separate constructs; this fit quite well. These two PRDs did not load on a single factor because they are not correlated highly with each other; probably this correlation is low because they were measured on different kinds of scales. ${ }^{3}$

\footnotetext{
${ }^{3}$ Both the PRD in family income and the PRD in male college graduate income were measured in dollars, while the other statistical perceptions were measured in percentages. The PRD in poverty is most highly correlated with the PRD in rates of undesirable behavior while the PRD in family income has similar correlations with the PRD in male college graduate income and the PRD in poverty. This pattern of correlations strongly sug-
}

However, our hypotheses about the PRD in economic disadvantage assume only that the PRDs in poverty and family income have the same consequences for racial attitudes. Our analysis supported this assumption, because these two PRDs showed similar correlations with each of the racial attitude variables: correlations with "still discrimination," were .130 and .116 respectively, and were .153 and .240 with "blacks don't make effort." By contrast, the other correlations between statistical perceptions and "blacks don't make effort" (.023 and .513) were far from either of the two correlations cited just above.

Where variables are correlated only moderately, but exert a similar effect (e.g., the

gests that the variables measured on the same scale showed increased correlations as a result of such measurement. Within SEM, such a situation sometimes can be handled with a model that allows for correlated errors of measurement of the statistical perception variables. However, we lacked a sufficient number of observed variables to permit identification of such a model; therefore we chose to use the index described above.

Table 2. Descriptive Statistics of Racial Attitude Measures

\begin{tabular}{lccccc}
\hline \hline Observed Variable & $N$ & Mean & SD & Min & Max \\
\hline Discrim. Important in Black Outcomes & 396 & 2.01 & .626 & 1 & 3 \\
Discrim. Limits Black Opportunities & 811 & 3.05 & 1.432 & 1 & 5 \\
Blacks Don't Stress Education & 776 & 2.66 & 1.414 & 1 & 5 \\
Blacks on Welfare Could Get Jobs & 245 & 3.56 & 1.441 & 1 & 5 \\
\hline
\end{tabular}

Note: As described in the text, AMOS 5 allows for unbiased coefficient estimates without using listwise deletion. 
Table 3. Standardized Loadings of Observed Variables on Latent Variable

\begin{tabular}{lccc}
\hline \hline Observed Variable & $\begin{array}{c}\text { PRD in } \\
\text { Undesirable } \\
\text { Behavior }\end{array}$ & $\begin{array}{c}\text { Still } \\
\text { Discrimination }\end{array}$ & $\begin{array}{c}\text { Blacks } \\
\text { Don't } \\
\text { Make Effort }\end{array}$ \\
\hline PRD in Welfare Rates & .706 & - & - \\
PRD in Birthrate Outside Marriage & .696 & - & - \\
Discrim. Important in Black's Outcomes & - & .701 & - \\
Discrim. Limits Black's Opportunities & - & - & -565 \\
Blacks Don't Stress Education & - & - & .546 \\
Blacks on Welfare Could Get Jobs & - & & \\
\hline
\end{tabular}

Note: $\mathrm{PRD}=$ perceived racial difference

variables that constitute SES or stress), it is common to combine these variables into an index. Thus we created a PRD index in economic status by standardizing both the PRD in family income and the PRD in poverty and then summing their standardized scores. (The correlation between this index and each of its constituent PRDs is .82.) Creating such an index offers two benefits. First, it enables us to present our results more parsimoniously. Second, the new measure has correlations with other statistical perception variables that are influenced less strongly by the measurement scale used.

Our final measurement model therefore contains three latent (unobserved) variables, each measured by two indicators. Two are the racial attitudes measured by the indicators discussed above. The other is "racial differences in undesirable behavior" which has two observed statistical perception indicators: beliefs about the racial difference in the welfare rate; and in the rate of unwed births. The PRD in male college graduate income is measured by a single observed indicator. The PRD in economic status is measured by the index composed of the PRDs in family income and in poverty rates. All errors of measurement are assumed to be uncorrelated.

This model fits very well. The comparative fit index is .966, and the RMSEA, which takes parsimony into account, is .049. The standardized loadings of the measurement model are displayed in Table 3; and the bivariate correlations among constructs in Table 4.

\section{Strategy for Testing Hypotheses}

We test Hypotheses 1 to 3 by examining bivariate correlations between PRDs and racial attitudes. To test Hypotheses $4 \mathrm{a}$ and $4 \mathrm{~b}$ however, we must examine the effects of some PRDs on "blacks don't make effort" while controlling for the other PRDs. To do so, we use a causal model in which all statistical perceptions predict both racial attitudes.

Testing and estimating such a model has two justifications. First, as we argued earlier, we suspect that the primary causal direction is from statistical perceptions to racial attitudes. Second, even when one does not know the causal order of variables, it is often useful to estimate equations specifying how some variables predict others (see e.g., Pedhazur 1982: pp 373). Indeed, many other studies use cross-sectional data to examine how well some racial attitudes and beliefs predict others (see, e.g., Bobo, Kluegel and Smith 1997; Brezina and Winder 2003; Sears, et al. 1997).

\section{RESULTS}

\section{Hypothesis Tests}

Hypothesis 1 predicts a positive bivariate correlation between the PRD in economic status and the belief that blacks fail to make the effort to succeed. In Table 4 we see that this hypothesis is supported: the correlation is 229 .

Hypothesis 2 predicts a positive correlation between the PRD in undesirable behavior and "blacks don't make effort." From Table 4 we can see that the correlation (.517) is not only in the predicted direction, but also much larger than the correlation between the PRD in economic status and "blacks don't make effort."

Hypothesis 3 predicts a strong positive correlation between the PRD in economic status and the PRD in undesirable behavior. 
Table 4. Correlations Among Statistical Perceptions and Racial Attitudes

\begin{tabular}{|c|c|c|c|c|c|}
\hline & $\begin{array}{c}\text { PRD } \\
\text { Economic } \\
\text { Status }\end{array}$ & $\begin{array}{c}\text { PRD } \\
\text { Male } \\
\text { College } \\
\text { Graduate } \\
\text { Income }\end{array}$ & $\begin{array}{c}\text { PRD } \\
\text { Undesirable } \\
\text { Behavior }\end{array}$ & $\begin{array}{c}\text { Still } \\
\text { Discrimination }\end{array}$ & $\begin{array}{l}\text { Blacks } \\
\text { Don't } \\
\text { Make } \\
\text { Effort }\end{array}$ \\
\hline $\begin{array}{l}\text { PRD } \\
\text { Economic } \\
\text { Status }\end{array}$ & 1.000 & - & - & - & - \\
\hline $\begin{array}{l}\text { PRD Male } \\
\text { College } \\
\text { Graduate } \\
\text { Income }\end{array}$ & $.287 * * *$ & 1.000 & - & - & - \\
\hline $\begin{array}{l}\text { PRD in } \\
\text { Undesirable } \\
\text { Behavior }\end{array}$ & $.628 * * *$ & $.121 * *$ & 1.000 & - & - \\
\hline $\begin{array}{l}\text { Still } \\
\text { Discrimination }\end{array}$ & $.176^{* *}$ & $.425 * * *$ & -.081 & 1.000 & - \\
\hline $\begin{array}{l}\text { Blacks Don't } \\
\text { Make Effort }\end{array}$ & $.229 * * *$ & .019 & $.517 * * *$ & $-.466 * * *$ & 1.000 \\
\hline
\end{tabular}

Notes: For each of the correlations involving two statistical perceptions, the standard error ranges between .035 and .039. For each of the two racial attitude latent variables, one question (observed variable) was asked of only half of the sample. Therefore, the correlations involving these latent variables had somewhat larger standard errors. The largest standard error is $.097 . \mathrm{PRD}=$ perceived racial difference.

$* *=p<.01 ; * * *=p<.001$ (two-tailed)

This is confirmed strongly, with a correlation of .628.

Table 5 shows dramatic support for Hypotheses $4 \mathrm{a}$ and $4 \mathrm{~b}$. When we control for other statistical perceptions, the moderatesized but statistically significant bivariate correlation between the PRD in economic status and "blacks don't make effort" is replaced by a small and nonsignificant standardized multiple regression coefficient. ${ }^{4} \mathrm{By}$

${ }^{4}$ Those who have misgivings about the causal assumptions in this model should note that when we compute the partial correlation between the PRD in economic status and the belief that blacks lack effort, controlling for the PRD in undesirable behavior, the results are very similar to those shown in the regression model. contrast, the effect of the PRD in undesirable behavior on "blacks don't make effort" remains strong, even when we control for other statistical perceptions.

Hypothesis 5 predicts a positive relationship between the perceived black-white economic difference, controlling for education, and belief in the continued existence of discrimination against blacks. This hypothesis is strongly confirmed, both when we examine the bivariate correlation between the PRD in male college graduate income and "still discrimination" (see Table 4) and when we control for other PRDs (see Table 5).

\section{Other findings}

In Table 5, we also note two other statis-

Table 5. Standardized Structural Equation Coefficients Predicting Racial Attitudes From Statistical Perceptions

\begin{tabular}{lcc}
\hline \hline & \multicolumn{2}{c}{ Dependent Variable } \\
\cline { 2 - 3 } Predictor & $\begin{array}{c}\text { Still } \\
\text { Discrimination }\end{array}$ & $\begin{array}{c}\text { Blacks Don't } \\
\text { Make Effort }\end{array}$ \\
\hline PRD Economic Status & $.240^{* *}$ & -.153 \\
PRD Male College Grad. Income & $.390^{* * *}$ & -.011 \\
PRD Undesirable Behavior & $-.279^{* *}$ & $.614^{* * *}$ \\
$R^{2}$ & .231 & .282 \\
\hline
\end{tabular}

Note: $\mathrm{PRD}=$ perceived racial difference

$* *=p<.01 ; * * *=p<.001$ (two-tailed) 
tically significant findings. Controlling for other statistical perception PRDs, (1) the greater the PRD in economic status, the greater the belief that there is still discrimination; and (2) the greater the PRD in undesirable behavior, the less the belief that there is still discrimination.

\section{Supplemental Analyses to Rule Out Alternative Interpretations}

One might question our method of testing our hypotheses on several grounds. First, the PRD in poverty may be more likely to evoke status generalization effects than would the PRD in family income. Using an index that combines these PRDs then would dilute the effect of the PRD in poverty. Second, the correlation between the PRDs in undesirable behavior and poverty may be so high because one of the indicators of undesirable behavior is welfare, which some would consider an obvious consequence of poverty. Third, the very high correlation between the PRD in undesirable behavior and the belief that "blacks don't make an effort" may be an artifact of the close relationship between one of the indicators of undesirable behavior, namely welfare rates, and attitudinal items which reflect the notion that blacks are lazy.

To address these concerns, we performed additional analyses in which we replaced the PRD in economic status with the PRD in poverty and replaced the PRD in undesirable behavior with the PRD in births outside marriage thereby removing welfare from the analysis. All hypotheses that were confirmed earlier were also confirmed in these supplemental analyses. In particular, the relationship between the PRD in poverty and the belief that "blacks don't make an effort" is not statistically significant, once we control for the PRD in births outside marriage. (The complete set of supplemental results is available on request.)

\section{DISCUSSION AND CONCLUSIONS}

\section{Summary}

In accordance with Brezina and Winder (2003), the greater the PRD in economic status, the greater the belief that blacks do not make an effort. When other statistical per- ceptions are controlled, however, the relationship between the PRD in economic status and the belief that blacks lack effort is not significant. By contrast, when other statistical perceptions are controlled, the greater the PRD in undesirable behavior, the greater the belief that blacks do not make an effort.

As hypothesized, the greater the PRD in economic status controlling for education, the more the respondents believe that blacks still experience discrimination. We also find that the greater the PRD in economic status, the greater the belief that discrimination continues, but this effect is not as strong as the effect of the PRD in economic status that controls for education. In addition, we find that the greater the PRD in undesirable behavior, the less the belief that blacks still experience discrimination. This suggests that the more strongly that people attribute economic failure to a lack of effort, the less they will attribute such failure to discrimination. Our results also support Gilens's (1999) point that being on welfare is not viewed simply as an indicator of poverty, but as a sign of socially undesirable behavior (laziness).

Because of evidence that many Americans do not understand numbers very well (see Paulos 1990), we would expect nontrivial amounts of randomness in answers to the questions on statistical perceptions. Even so, we found effects that were at least moderately large. ${ }^{5}$ Although facts and beliefs about facts sometimes can be interpreted in more than one way, our evidence suggests that each of the perceived racial differences we have examined here is more amenable to one of the interpretations (discrimination or lack of effort) than to the other.

\section{Effects of More Accurate Information on Whites' Racial Attitudes}

We now try to gain a sense of the effect that more accurate information might exert on whites' attitudes. To do so, we examine both the direction of errors in the public's statistical perceptions (Table 1) and the

\footnotetext{
${ }^{5}$ We also considered the possibility that education moderates the relationship between attitudes and statistical perceptions. We found no evidence of this, however, when we divided the sample by education.
} 
effect of each statistical perception on racial attitudes (Table 5).

The classic literature on prejudice (see, e.g., Allport 1954) suggests that stereotypes (mental pictures) distort reality so that people's view of outgroups is more negative than is justified by the facts, and so that people exaggerate differences between groups (see LeVine and Campbell 1972).

The data used by Brezina and Winder (2003) cannot tell us whether respondents exaggerated the economic differences between blacks and whites. Brezina and Winder (2003:415), however, use results reported in Gilens (1999) to argue that whites overestimate the racial difference in economic status. Yet, as shown in Table 1, our respondents underestimated the racial difference in both income and poverty rates.

To resolve the apparent contradiction between our results and those of Gilens (1999), we observe that Gilens (p. 137) actually reports that whites overestimate the proportion of poor people who are black. This finding, however, does not show that whites overestimate the relationship between race and poverty. Instead, it could result from whites' overestimating the proportion of blacks in the American population. (For evidence that whites in fact make this error, see Gilens, 1999:138; Nadeau, Niemi, and Levine 1993; Sigelman and Niemi, 2001.)

Thus we have seen that the perceived racial differences in economic status, (both controlling for education, and not controlling for it), are related positively to the belief that there is still discrimination; and second, that whites underestimate these racial differences. These findings indicate that accurate knowledge of the magnitude of these racial differences would lead to a greater belief that there is still discrimination against blacks.

Moreover, in line with Kluegel (1990), our data set shows that the belief that there is still discrimination is correlated strongly with support for affirmative action. Thus our results also suggest that more accurate knowledge of the economic gap, especially controlling for education, would make whites more favorable to affirmative action.

Also in contrast to the view that stereotypes generally exaggerate differences between ingroups and outgroups, whites substantially underestimated the racial difference in rates of births outside marriage; they also underestimated the racial difference in rates of welfare dependence.

The findings, as reported above, also suggest that whites would be more negative towards blacks if they perceived a larger racial difference in rates of undesirable behavior. Thus our results suggest the unhappy conclusion that more accurate information actually might increase the number of whites who believe that blacks do not make sufficient effort to help themselves.

Therefore one way to limit negative stereotypes would be to avoid dissemination of such data. Our results, however, also suggest that (1) if there were a decrease in the actual racial difference in rates of undesirable behaviors (e.g. through decreased rates among blacks) and (2) if this decrease caused whites to perceive smaller racial difference in these rates, then whites' attitudes would become more positive. As we discuss below, this actually may have occurred since these data were collected.

\section{Status Generalization Theory Revisited}

As stated earlier, the perception that blacks' rates of undesirable behavior are higher than whites' rates exerts a large direct effect on negative stereotyping. By contrast, the perception that blacks are economically disadvantaged has an effect that is not statistically significant.

If these results are to be compatible with status generalization theory, the perception that blacks are economically disadvantaged must cause the perception that their rates of undesirable behavior are high. Although the high correlation between those perceptions is consistent with this causal mechanism, it is far from proof. If the perceived racial differences in undesirable behaviors were considerably greater than the actual racial differences, this finding would suggest that status generalization contributed substantially to the PRD in undesirable behaviors. As shown above, however, most respondents underestimated the racial differences in these behaviors. 
Moreover, examining the effects of the 1996 national restrictions on welfare suggests two points that are contrary to the status generalization explanation. First, the PRD in undesirable behavior can decrease substantially even if the PRD in economic status changes only minimally; second, this change in the PRD in undesirable behavior can cause a substantial change in the attitudes towards black people.

In the years following these welfare restrictions, survey evidence suggests that the public believed that the welfare rate had decreased substantially. ${ }^{6}$ We have two pieces of evidence for this assertion. First, as the welfare law was being passed, a general public survey (Health News Index Poll 1996) asked people to indicate their understanding of its effect. A large majority (75\%) of respondents understood that the new law would "limit the amount of time low-income women and children can receive welfare benefits over their lifetime."

Second, the General Social Survey (GSS) results suggest that the public believed this law actually had reduced the rates of welfare. When the 1994 GSS asked "Are we spending too much, too little, or about the right amount on welfare?" 60 percent said "too much." When the same question was asked in the 1998 GSS, only 43 percent said "Too much."

The critical aspect for our argument is the PRD of welfare dependence. If the perceived overall rate decreased, however, then even if the ratio of the perceived blacks' and whites" rates remained the same, the perceived difference between these two rates also would decrease.

We now examine the GSS data of 1990 and 1998 to see how this change may have affected those perceptions and beliefs that are the focus of this paper. ${ }^{7}$ Using the measures proposed by Brezina and Winder (2003:409) we find that the perception of blacks' economic disadvantage decreased

\footnotetext{
${ }^{6}$ This is true even though census data indicated that the actual rate of poverty and welfare participation had declined only slightly (Lester and Tin 2004).

${ }^{7}$ Some of these numbers were reported in Brezina and Winder (2003). We thank Timothy Brezina for supplying some of the other descriptive statistics for these variables for those two years.
}

slightly, from 1.53 to 1.25 . Yet, the tendency to stereotype blacks as lazy decreased more dramatically, ${ }^{8}$ from 1.34 to .71 . Even more important, the unstandardized slope of perceived economic disadvantage predicting negative stereotyping decreased from .415 to .310 (for this difference, $t(2006)=2.10 p<$ $.05)$; the intercept decreased dramatically from .705 to $.323(t(2006)=4.02, p<.001)$.

Thus, at the end of a period in which we believe that the PRD in one of the undesirable behaviors declined, two things happened. First, at any given level of perceived economic disadvantage, less negative stereotyping of blacks occurred in 1998 than in 1990. Second, viewing blacks as poor, had a smaller bivariate association with negative stereotyping in 1998 than in 1990. Both of these facts raise questions about whether the status generalization effect adequately explains current negative attitudes towards blacks.

\section{Limitations; Directions for Future Research}

We argued that the primary direction of the causal relationship between statistical perceptions and racial attitudes is from statistical perceptions. Yet assessing the size of the causal effect in each direction is an important task that requires more than our cross-sectional data.

This can be accomplished in several ways. First, if the racial statistics change, it also would be interesting to see how this change affects the statistical perceptions and their relationship to the various attitudes. Second, one could conduct some experiments. Subjects could be provided with various alternative sets of fictional data about the black-white difference in economic status

\footnotetext{
${ }^{8}$ Brezina and Winders's key measures were based on the following questions. One asked respondents to rate rate blacks and whites separately on a scale from 1 ("almost all are hard working") to (7 "almost all are lazy"). A respondent's negative stereotype measure was his or her laziness rating for blacks minus the corresponding rating for whites. In other questions, respondents were asked to rate the economic status of each race on a scale from 1 ("almost all are rich") to 7 ("almost all are poor"). A respondent's perception of blacks' economic disadvantage was his or her rating for blacks' being poor minus the corresponding rating for whites' being poor.
} 
and/or undesirable behavior, and then could be measured on dependent variables similar to those we have used here. Third, one could extend this study to encompass attitudes towards other ethnic groups. It would be especially valuable to find situations where some undesirable behaviors are less common in the economically disadvantaged group than in the more advantaged group. Such a test case might involve some immigrant groups who record lower-than-average use of welfare despite lower-than-average incomes (see Fix and Passel 1994: 63). Then one also would want analogous data on statistical perceptions, as well as on attitudes towards the disadvantaged groups.

\section{REFERENCES}

Allison, Paul D. 2002. Missing Data. Thousand Oaks, CA: Sage.

Allport, Gordon W. 1954. The Nature of Prejudice. Reading, MA: Addison-Wesley.

Al-Zahrani, Saad Said A. and Stan A. Kaplowitz. 1993. "Attributional Biases in Individualistic and Collectivistic Cultures: A Comparison of Americans and Saudis." Social Psychology Quarterly 56:223-33.

Arbuckle, James. 1996. "Full Information Estimation in the Presence of Incomplete Data." Pp. 243-76 in Advanced Structural Equation Modeling: Issues and Techniques, edited by George A. Marculides and Randall Schumacker. Mahwah, NJ: Erlbaum.

Arbuckle, James and Werner Wothke. 1999. AMOS 4.0 User's Guide. Chicago: SPSS.

Armstrong, G. Blake. 1991. "Television News and Entertainment Exposure, Educational Experiences, and College Students' Race Related Beliefs: Material Factors and Symbolic Racism." Presented at the meetings of the Association for Education in Journalism and Mass Communication, August, Boston.

Bobo, Lawrence D., James R. Kluegel, and Ryan Smith. 1997. "Laissez-Faire Racism: The Crystallization of a Kinder, Gentler AntiBlack Ideology." Pp. 15-42 in Racial Attitudes in the 1990s: Continuity and Change, edited by Steven A. Tuch \& Jack K. Martin. Westport, CT: Praeger.

Bobo, Lawrence D., and Michael P. Massagli. 2001. "Stereotyping and Urban Inequality." Pp. 89-162 in Urban Inequality: Evidence From Four Cities, edited by Alice O'Conner, Chris Tilly, and Lawrence D. Bobo. New York: Russell Sage Foundation.
Bollen, Kenneth. 1989. Structural Equations With Latent Variables. New York: Wiley.

Brezina, Timothy and Kenisha Winder. 2003. "Economic Disadvantage, Status Generalization, and Negative Racial Stereotyping by White Americans." Social Psychology Quarterly 66:402-18.

Cook, Karen S. 1975. "Expectations, Evaluations, and Equity." American Sociological Review 40:372-88.

Fix, Michael and Jeffrey S. Passel. 1994. Immigration and Immigrants: Setting the Record Straight. Washington, DC: Urban Institute.

Gilens, Martin. 1996. "Race and Poverty in America: Public Misperceptions and the American News Media." Public Opinion Quarterly 60:515-41.

1999. Why Americans Hate Welfare: Race, Media, and the Politics of Anti-Poverty Politics. Chicago: University of Chicago Press.

Hammond, Kenneth. R. 1948. "Measuring Attitudes by Error Choice: An Indirect Method." Journal of Abnormal and Social Psychology 43:38-48.

Health News Index Poll. 1996. Survey by Henry J. Kaiser Family Foundation, Harvard School of Public Health. Data provided by Roper Center for Public Opinion Research, University of Connecticut.

Heider, Fritz. 1958. The Psychology of Interpersonal Relations. New York: Wiley.

Jones, Edward E. and Keith E. Davis. 1965. "From Acts to Dispositions: The Attribution Process in Person Perception." Pp. 219-66 in Advances in Experimental Social Psychology, edited by Leonard Berkowitz. New York: Academic Press.

Kaplowitz, Stan A., Bradley J. Fisher and Clifford L. Broman. 2003. "How Accurate Are Perceptions of Social Statistics About Blacks and Whites? Effects of Race and Education." Public Opinion Quarterly 67: 237-43.

Katz, Irwin and R. Glen Hass. 1988. "Racial Ambivalence and American Value Conflict: Correlation and Priming Studies of Dual Cognitive Structures." Journal of Personality and Social Psychology 55:893-905.

Kennedy, John F. (1964) "Civil Rights Message to the Nation (June 12, 1963) ." Pp. 110-14 in The Kennedy Years and the Negro, edited by Doris E. Saunders. Chicago: Johnson.

Kinder, Donald R. and David O. Sears. 1981. "Prejudice and Politics: Symbolic Racism vs. Racial Threats to the Good Life." Journal of Personality and Social Psychology 40: 414-31.

Kluegel, James R. 1990. "Trends in Whites' 
Explanations of the Gap in Black-White Socio-Economic Status, 1977-1989." American Sociological Review 55:512-25.

Kluegel, James R. and Elliot R. Smith. 1986. Beliefs About Inequality: Americans' Views About What Is And What Ought To Be. Hawthorne, NY: Aldine.

Lester, Gordon H. and Jan Tin. 2004. "Dynamics of Economic Well-Being: Program Participation, 1996 to 1999: Who Gets Assistance?" Washington DC: US Bureau of the Census.

LeVine, Robert. A. and Donald. T. Campbell. 1972. Ethnocentrism: Theories of Conflict, Ethnic Attitudes and Group Behavior. New York: Wiley.

Miller, Joan. 1984. "Culture and Development of Everyday Social Explanation." Journal of Personality and Social Psychology 46: 961-78.

Myrdal, Gunnar. 1944. An American Dilemma: The Negro Problem and Modern Democracy. New York: Harper.

Nadeau, Richard, Richard G. Niemi and Jeffrey Levine. 1993. "Innumeracy about Minority Populations." Public Opinion Quarterly 57 (March): 332-47.

Paulos, John A. 1990. Innumeracy. New York: Vintage.

Pedhazur, Elazar. 1982. Multiple Regression in Behavioral Research (2nd edition). New York: Holt, Rinehart, Winston.

Report of the National Advisory Commission on
Civil Disorders. 1968. Washington DC: US Government Printing Office.

Ridgeway, Cecilia L. 2000. "The Formation of Status Beliefs: Improving Status Construction Theory." Pp. 77-102 in Advances in Group Processes, vol. 17, edited by Shane R. Thye, Edward J. Lawler, Michael W. Macy, and Henry A. Walker. Stamford, CT: JAI.

Ross, Lee. 1977. "The Intuitive Psychologist and His Short-Coming: Distortions in the Attribution Process." Pp. 173-220 in Advances in Experimental Social Psychology, vol. 10, edited by Leonard Berkowitz. New York: Academic Press.

Sears, David O., Colette Van Laar, Mary Carrillo and Rick Kosterman. 1997. "Is It Really Racism? The Origins of White American's Opposition of Race-Targeted Policies." Public Opinion Quarterly 61:16-53.

Sigelman, Lee and Richard G. Niemi, 2001. "Innumeracy about Minority Populations: African-Americans and Whites Compared." Public Opinion Quarterly 65: 86-94.

Sniderman, Paul M. and Thomas Piazza. 1993. The Scar of Race. Cambridge, MA: Harvard University Press.

United States Bureau of the Census (1990). Measuring the Effect of Benefits and Taxes on Income and Poverty 1989 . Current population reports, Series P-60, Consumer income; no 169-RD. Washington, DC: U.S. Dept. of Commerce, Bureau of the Census.

Stan A. Kaplowitz is professor of sociology at Michigan State University. He has recently published studies of doctor- patient communication, perceptions of power, attitudes towards a campus riot, attitudes towards food safety regulations, and attitudinal oscillation. He is currently estimating lead poisoning risk of children from data about neighborhood, housing and family characteristics in a project that has been funded by the CDC and is now funded by federal Medicaid.

Clifford L. Broman is professor of sociology at Michigan State University. He is currently involved in a project funded by NIDA concerning race and adolescent substance use. Other current projects involve the epidemiology of substance use, and the politics and consequences of racial identification.

Bradley J. Fisher is professor of gerontology and psychology in the Psychology Department at Missouri State University. His research interests include the self-concept across the lifespan, stereotyping and race relations, factors associated with subjective well-being in later life, and innovative teaching techniques. 